\title{
Routing Protocols in MANET: A Survey
}

\author{
Swati Puri \\ M.Tech Student \\ CSE Department,SBSCET \\ Ferozepur, Punjab (INDIA)
}

\author{
Vishal Arora \\ Assistant Professor \\ CSE Department,SBSCET \\ Ferozepur, Punjab (INDIA)
}

\begin{abstract}
Mobile means moving and ad hoc means temporary with no any fixed infrastructure so mobile ad hoc networks are a class of temporary networks in which nodes are moving without any fixed infrastructure or centralized management. Due to the various applications that use MANETs are such as battlefield, emergency services, and disaster discovery, MANETs suggest many advantages too many organizations that need wireless roaming. Routing in MANETs is a not easy task and has expected a large amount of attention from researchers around the world. To overcome this difficulty a number of routing protocols have been developed and the number is silent increasing day by day. It is rather hard to determine which of the protocols may complete well under a number of different network scenarios such as network size and topology etc. In this paper we present a review of the existing routing protocols with their characteristics and functionality. In future this will help out the researchers to get an overview of the existing protocols.
\end{abstract}

\section{Keywords}

Mobile Ad-hoc Network, Ad-Hoc routing table, Ad-Hoc routing protocol, Ad-Hoc Network.

\section{INTRODUCTION}

A mobile ad hoc network (MANET) consists of a set of mobile hosts that know how to communicate with each other without the help of base stations [1]. As shown in Fig. 1, the topology of a MANET can be extremely dynamic due to the mobility of mobile nodes [2]. The formation of mobile computing and communication devices (e.g., cell phones, laptops, personal digital assistants) is driving a new change in our information culture. Wireless networks consist of a number of nodes which communicate by each other over a wireless channel. There are now two variations of mobile wireless networks: infrastructure networks and infrastructure less networks. The infrastructure networks are the one, in which mobile devices communicate with base stations that are connected to fixed network infrastructure. Each node in the infrastructure networks is within the range of a fixed access point like base station [3]. Infrastructure less wireless networks is a major class of wireless networks that is greatest appropriate for scenarios where there is demand of temporary and localized telecommunication demand. Such networks consist of wireless devices that can form a network alone without the need for pre-deployed telecommunication infrastructures such as base-stations and access points [4].

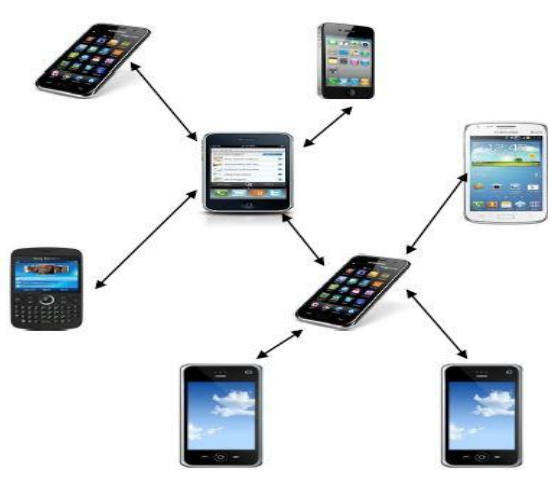

Fig 1: MANET Network

\section{RESEARCH AND DEVELOPMENT IN MANET}

Mobile Ad hoc network characterized into first, second and third generation. The first generation of ad hoc network can be traced back to 1970's. In 1970's, these are called Packet Radio Network (PRNET)

The PRNET then evolved into the Survivable Adaptive Radio Network (SURAN) in the early 1980's. SURAN provided some profit by improving the radio performance.

In 1990's the performance group of MANET is born in Internet Engineering Task Force (IETF) who worked to regular routing protocols for MANET and gives rise to the development of various mobile devices like PDA's ,palmtops, notebooks, etc [5].

\subsection{Characteristic in MOBILE AD-HOC NETWORKS}

\subsubsection{Dynamic Topologies}

Nodes are free to go randomly with different speeds; therefore the network topology may change randomly and at irregular times.

\subsubsection{Energy Constrained Operation}

Some or all of the nodes in an ad hoc network may rely on batteries or other exhaustible means used for their energy. The mainly important system design optimization criteria can be energy conservation.

\subsubsection{Limited Bandwidth}

Wireless links continue to have much lower capacity than infrastructure networks. The realized throughput of wireless communication - after accounting for the effects of multiple access and interference conditions, etc, is often much less than a radio's maximum transmission rate. 


\subsubsection{Security Threats}

Mobile wireless networks are generally more level to physical security threats than fixed-cable nets. The increased possibility of eavesdropping spoofing and minimization of denial-of-service type attacks should be carefully considered [6].

\subsection{Issues in MANETS Networks \\ 2.2.1Routing}

Routing is one of the most complicated problems to solve as ad hoc networks have a correct connectivity to other devices in its neighborhoods. Because of multi hop routing no default route is available. Each node acts as a router and forwards each other's packets to allow in sequence sharing between mobile nodes.

\subsubsection{Security}

Clearly a wireless link is much more at risk than a wired link. The user can add false information into routing packets and cause routing loops, long time-outs and advertisements of false or old routing table updates. Security has few unsolved issues that are important to solve to make the ad hoc network into a good solution.

\subsubsection{Quality of Service (QoS)}

QoS is a complex task for the developers, because the topology of an ad hoc network will regularly change. Reserving resources and supporting a certain quality of service, while the network situation constantly changes, is very challenging [7].

\subsection{Application in MANET}

\subsubsection{Military Battlefield}

Ad-Hoc networking would agree to the military to receive advantage of routine network technology to keep an information network between the soldiers, vehicles, and military information head quarter.

\subsubsection{Collaborative Work}

For various business environments, the need for common computing might be more important outside office environments than inside and where people do need to have external meetings to assist and exchange information on a given project.

\subsubsection{Local Level}

Ad-Hoc networks can separately link an instant and shortterm multimedia network using notebook computers to extend and share information with participants. E.g. conference or classroom.

\subsubsection{Personal area network and Bluetooth}

A personal area network is a little range, localized network here nodes are usually connected with a given person. Short range MANET such as Bluetooth.

\subsubsection{Commercial Sector}

Ad hoc can be used in urgent situation operations for failure assistance efforts, e.g. in fire, flood, or earthquake. Emergency rescue operations must take position where nonexisting or injured communications infrastructure and fast deployment of a communication network is required [8].

\section{CATEGORIZATION OF PRESENT ROUTING PROTOCOLS IN (MANET)}

In the ad hoc networks, every node should be capable to forward data for other nodes. So different routing schemes have been offered to supply enough performance of ad hoc networks. Ad hoc routing is classified into proactive routing and reactive routing and hybrid routing protocols [2]. As shown in Fig. 2.

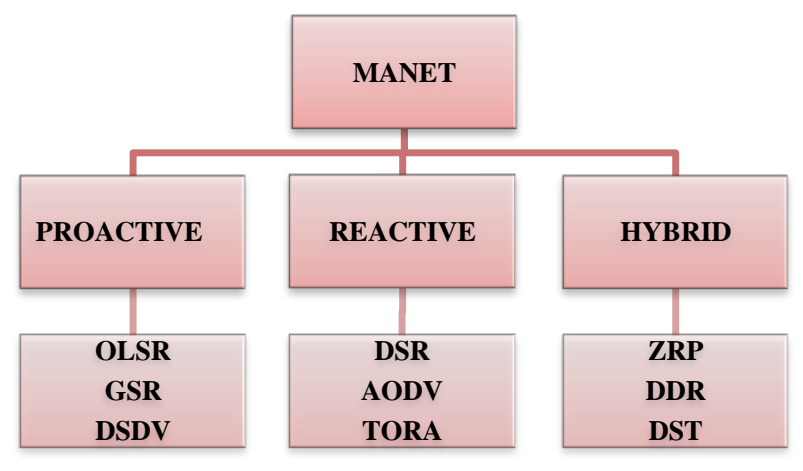

Fig 2: Routing Protocols for MANET

\subsection{Proactive Routing Protocols/Table Driven}

In table driven routing protocols, the protocols accepted and up-to-date routing in series to all nodes is maintained at each node where as in on-demand routing the routes are produced only when prefer by the source host [9]. Nodes sometimes look for routing information within a network. The fixed cost of these protocols is possible, because it is free to the traffic profiles and has a fixed upper bound. This is advantage of proactive routing protocols e.g. OLSR, GSR, DSDV [10].

\subsubsection{Optimized Link State Routing (OLSR)}

OLSR is an optimization of pure link state algorithm, uses the theory of Multi point Relays (MPR) for forwarding control traffic, proposed for distribution into the entire network. The MPR set is chosen such that it covers all nodes that are two hops away. OLSR works with a periodic replace of messages like Hello messages and Topology Control (TC) message only through its MPR. The parameters used by OLSR to control the protocol overheads are Hello-interval parameter, TC interval parameter, MPR reporting parameter and TCredundancy parameter [11].

\subsubsection{Global state routing (GSR)}

The GSR protocol is based on the fixed Link State algorithm. GSR has enhanced the way in sequence is distributed in Link State algorithm by restricting the update messages among intermediate nodes only. In GSR, every node maintains a link state table based on the up-to-date information expected from neighboring nodes, and from time to time exchanges its link state information with neighboring nodes only. This has much reduced the number of control message transmitted during the network. The size of update messages is rather large, and as the size of the network grows they will get even larger [12].

\subsubsection{Destination Sequenced Distance Vector $(D S D V)$}

In DSDV protocol every node maintains routing in sequence for all known destinations. The routing information is updated from time to time. Each node maintains a table, which contains information for all existing destinations, the next node to arrive at the destination, number of hops to reach the 
destination and sequence number. The nodes from time to time send this table to all neighbors to maintain the topology, which adds to the network overhead. Each entrance in the routing table is marked with an order number assigned by the destination node. The series numbers allow the mobile nodes to distinguish stale routes from new ones, so avoiding the structure of routing loops [13]. The summary of above discussion is shown in Table 1.

Table 1. Proactive routing protocols/table driven

\begin{tabular}{|c|c|c|c|c|c|c|}
\hline Protocol & $\begin{array}{c}\text { Routing } \\
\text { Protocol } \\
\text { Class }\end{array}$ & $\begin{array}{c}\text { Routing } \\
\text { Structure }\end{array}$ & $\begin{array}{l}\text { Multiple } \\
\text { Routes }\end{array}$ & $\begin{array}{l}\text { Route } \\
\text { Metric } \\
\text { Method }\end{array}$ & $\begin{array}{c}\text { Route } \\
\text { Maintenance }\end{array}$ & $\begin{array}{c}\text { Advantage/ } \\
\text { Disadvantage }\end{array}$ \\
\hline $\begin{array}{l}\text { Optimized link } \\
\text { state routing } \\
(\text { OLSR })\end{array}$ & $\begin{array}{c}\text { Proactive } \\
\text { Routing } \\
\text { Protocol }\end{array}$ & Flat & No & Periodic & $\begin{array}{l}\text { Reduces control } \\
\text { overhead using } \\
\text { Multipoint Relay }\end{array}$ & $\begin{array}{c}\text { Reduced control } \\
\text { overhead and } \\
\text { contention / 2-hop } \\
\text { neighbor knowledge } \\
\text { required }\end{array}$ \\
\hline $\begin{array}{c}\text { Global state } \\
\text { routing (GSR) }\end{array}$ & $\begin{array}{c}\text { Proactive } \\
\text { Routing } \\
\text { Protocol }\end{array}$ & Flat & No & $\begin{array}{c}\text { Periodic and } \\
\text { local }\end{array}$ & $\begin{array}{l}\text { Localized } \\
\text { updates }\end{array}$ & $\begin{array}{c}\text { Localized updates / } \\
\text { High memory overhead }\end{array}$ \\
\hline $\begin{array}{l}\text { Destination- } \\
\text { sequenced } \\
\text { distance vector } \\
\text { (DSDV) }\end{array}$ & $\begin{array}{c}\text { Proactive } \\
\text { Routing } \\
\text { Protocol }\end{array}$ & Flat & No & $\begin{array}{c}\text { Periodic and } \\
\text { as required }\end{array}$ & Loop free & $\begin{array}{c}\text { Loop free / High } \\
\text { overhead }\end{array}$ \\
\hline
\end{tabular}

\subsection{Reactive Routing Protocols}

The on demand routing protocols, "on demand" means that it builds routes between nodes only as preferred by source nodes. It maintains these routes as long as they are required by the sources [9].The reactive (on-demand) routing protocols describe the perfect nature of ad hoc network, which is much more dynamic than infra structured networks. In its place of from time to time updating the routing information, the reactive routing protocols update routing information when a routing need is presented, thus reducing the control overhead, mainly in high mobility networks where the periodical update will guide to significant useless overhead e.g. AODV, DSR, TORA [14].

\subsubsection{Ad Hoc On-Demand Distance Vector (AODV)}

AODV is a mixture of on-demand and distance vector i.e. hop-to-hop routing methodology. When a node wants to know a route to a particular destination it creates a ROUTE REQUEST. Then the route request is forwarded by intermediate nodes which also produce a reverse route for itself to destination. When the demand reaches a node with route to destination it creates again a REPLY which contains the number of hops that are need to reach the destination. All nodes that play a part in forwarding this reply to the source node create a forward route to destination. This route produced from each node from source to destination is a hopby-hop state and not the complete route as in source routing [11].

\subsubsection{Dynamic Source Routing Protocol (DSR)}

In Dynamic Source Routing, beginning node generates Route Request (RREQ), which is sent over data packet and It specifies source node as well as destination. Afterwards, the packet sends by flooding algorithm in MANET. Each node receives RREQ packet and does not know about the route to the destination so combine its name on the list which is placed on packet's header then broadcast packet. If each node cannot transmit the data packet to other nodes in the MANET, then a Route Error (RERR) data packet is generated and retransmitted it on the route [15].

\subsubsection{Temporally Ordered Routing Algorithm (TORA)}

Temporarily ordered routing algorithm (TORA) is highly adaptive, loop-free, distributed routing algorithm based on the idea of link exchange. It uses directed acyclic graphs (DAG) to explain the Routes both as upstream or downstream. TORA involves four major functions: creating, maintaining, erasing and optimizing routes. As every node must have a height, some node which does not have a height is considered as an erased node and its height is considered as null. Sometimes the nodes are certain new heights to get better the linking structure. This purpose is called optimization of routes [16]. The summary of above discussion is shown in Table 2. 
Table 2. Reactive routing protocols

\begin{tabular}{|c|c|c|c|c|c|c|}
\hline Protocol & $\begin{array}{c}\text { Routing } \\
\text { Protocol } \\
\text { Class }\end{array}$ & $\begin{array}{l}\text { Routing } \\
\text { Structure }\end{array}$ & $\begin{array}{c}\text { Multiple } \\
\text { Routes }\end{array}$ & $\begin{array}{l}\text { Route Metric } \\
\text { Method }\end{array}$ & $\begin{array}{c}\text { Route } \\
\text { Maintenance }\end{array}$ & Advantage/Disadvantage \\
\hline $\begin{array}{l}\text { Ad hoc on- } \\
\text { demand } \\
\text { distance } \\
\text { vector } \\
\text { (AODV) }\end{array}$ & $\begin{array}{l}\text { Reactive } \\
\text { Routing } \\
\text { Protocol }\end{array}$ & Flat & No & $\begin{array}{l}\text { Freshest and } \\
\text { shortest path }\end{array}$ & Route Table & $\begin{array}{l}\text { Adaptable to highly } \\
\text { dynamic } \\
\text { Topologies / Scalability } \\
\text { problems, large delays, } \\
\text { hello messages }\end{array}$ \\
\hline $\begin{array}{c}\text { Dynamic } \\
\text { source routing } \\
\text { (DSR) }\end{array}$ & $\begin{array}{l}\text { Reactive } \\
\text { Routing } \\
\text { Protocol }\end{array}$ & Flat & Yes & $\begin{array}{c}\text { Shortest path, or } \\
\text { next available } \\
\text { in route cache }\end{array}$ & Route Cache & $\begin{array}{c}\text { Multiple routes, } \\
\text { Promiscuous } \\
\text { Overhearing / Scalability } \\
\text { problems due to source } \\
\text { routing } \\
\text { and flooding, large delays }\end{array}$ \\
\hline $\begin{array}{l}\text { Temporally } \\
\text { ordered } \\
\text { routing } \\
\text { algorithm } \\
\text { (TORA) }\end{array}$ & $\begin{array}{l}\text { Reactive } \\
\text { Routing } \\
\text { Protocol }\end{array}$ & Flat & Yes & $\begin{array}{l}\text { Shortest path, or } \\
\text { next available }\end{array}$ & Route Table & $\begin{array}{c}\text { Multiple routes / } \\
\text { Temporary routing loops }\end{array}$ \\
\hline
\end{tabular}

\subsection{Hybrid Routing Protocols}

The hybrid routing protocols that have the advantage of both proactive and reactive routing protocols to balance the delay and control overhead (in terms of organize packages). Hybrid routing protocols try to maximize the profit of proactive routing and reactive routing by utilizing proactive routing in small networks (in order to decrease delay), and reactive routing in large scale networks (in order to decrease control overhead) e.g. ZRP,DST, DDR [14].

\subsubsection{Zone Routing Protocol (ZRP)}

In ZRP the nodes control a routing zone, which defines a collection that each node is required to maintain network connectivity proactively. Consequently, for nodes inside the routing zone, routes are immediately accessible. For nodes that lie outer the routing zone, routes are determined ondemand (i.e. reactively), and it can use any on-demand routing protocol to verify a route to the required destination [12].

\subsubsection{Distributed Spanning Tree (DST)}

The nodes in the network are grouped into a number of trees. Each tree has two types of nodes; route node, and internal node. The root controls the collection of the tree and whether the tree can combine with a new tree, and the rest of the nodes within each tree are the regular nodes. All node can be in one three different states; router, merge and configure depending on the category of task that it trying to perform. DST proposes two strategies to terminate a route between a source and a destination pair: Hybrid Tree Flooding (HTF), Distributed Spanning Tree (DST) shuttling [16].

\subsubsection{Distributed Dynamic Routing (DDR)}

Planed a tree based routing protocol without the required of a root node. The trees are constructed using constant beaconing messages, which are exchanged by nearest nodes only. The DDR algorithm include the following six phases: (i) preferred neighbor election; (ii) intra-tree clustering; (iii) inter-tree clustering; (iv) forest construction; (v) zone naming; and (vi) zone partitioning [17].The summary of above discussion is shown in Table 3. 
Table 3. Hybrid routing protocols

\begin{tabular}{|c|c|c|c|c|c|c|}
\hline Protocol & $\begin{array}{c}\text { Routing } \\
\text { Protocol } \\
\text { Class }\end{array}$ & $\begin{array}{l}\text { Routing } \\
\text { Structure }\end{array}$ & $\begin{array}{l}\text { Multiple } \\
\text { Routes }\end{array}$ & $\begin{array}{l}\text { Route Metric } \\
\text { Method }\end{array}$ & $\begin{array}{c}\text { Route } \\
\text { Maintenance }\end{array}$ & Advantage/Disadvantage \\
\hline $\begin{array}{l}\text { Zone } \\
\text { routing } \\
\text { protocol } \\
\text { (ZRP) }\end{array}$ & $\begin{array}{l}\text { Hybrid } \\
\text { Routing } \\
\text { Protocol }\end{array}$ & Flat & No & Shortest path & $\begin{array}{l}\text { Intrazone and } \\
\text { interzone tables }\end{array}$ & $\begin{array}{l}\text { Reduce retransmissions / } \\
\text { Overlapping zones }\end{array}$ \\
\hline $\begin{array}{l}\text { Distributed } \\
\text { spanning } \\
\text { trees based } \\
\text { routing } \\
\text { protocol } \\
\text { (DST) }\end{array}$ & $\begin{array}{l}\text { Hybrid } \\
\text { Routing } \\
\text { Protocol }\end{array}$ & Hierarchical & $\begin{array}{c}\text { Yes, if } \\
\text { available }\end{array}$ & $\begin{array}{l}\text { Forwarding } \\
\text { using the tree } \\
\text { neighbors' } \\
\text { and the } \\
\text { bridges using } \\
\text { shuttling }\end{array}$ & Route tables & $\begin{array}{l}\text { Reduce retransmissions / Root } \\
\text { node }\end{array}$ \\
\hline $\begin{array}{l}\text { Distributed } \\
\text { dynamic } \\
\text { routing } \\
\text { (DDR) }\end{array}$ & $\begin{array}{l}\text { Hybrid } \\
\text { Routing } \\
\text { Protocol }\end{array}$ & Hierarchical & $\begin{array}{c}\text { Yes, it } \\
\text { alternate } \\
\text { Gateway } \\
\text { nodes are } \\
\text { available }\end{array}$ & Stable routing & $\begin{array}{l}\text { Intrazone and } \\
\text { interzone table }\end{array}$ & $\begin{array}{c}\text { No zone map or } \\
\text { zone coordinator / Preferred } \\
\text { neighbours may } \\
\text { become bottlenecks }\end{array}$ \\
\hline
\end{tabular}

\section{COMPARISON OF ROUTING} PROTOCOL
Table 4 shows the comparison of three routing protocols (Proactive, Reactive, and Hybrid).

Table 4. Comparison of routing protocols

\begin{tabular}{|c|c|c|c|}
\hline Parameters & Proactive & Reactive & Hybrid \\
\hline Storage Requirement & Higher & $\begin{array}{l}\text { Dependent on no. of } \\
\text { Routes maintained or needed }\end{array}$ & $\begin{array}{l}\text { Depends on size of each } \\
\text { zone or cluster }\end{array}$ \\
\hline Routing Schema & $\begin{array}{c}\text { On } \\
\text { demand }\end{array}$ & Table driven & Combination of both \\
\hline Mobility Support & $\begin{array}{c}\text { Route } \\
\text { Maintenance }\end{array}$ & Periodical updates & Combination of both \\
\hline Routing Overhead & Low & High & Medium \\
\hline Routing Information & Keep stored in table & Doesn't store & $\begin{array}{l}\text { Depends on } \\
\text { requirement }\end{array}$ \\
\hline Storage Capacity & Low generally & High , due to the routing tables & $\begin{array}{c}\text { Depends on the size of } \\
\text { Zone }\end{array}$ \\
\hline
\end{tabular}




\begin{tabular}{|c|c|c|c|}
\hline Routing Philosophy & Mostly flat & Flat & Hierarchical \\
\hline Delay & Low & High & $\begin{array}{c}\text { Low for local destinations and } \\
\text { high for Inter-zone }\end{array}$ \\
\hline
\end{tabular}

\section{CONCLUSION}

In this paper, we have presented the classification of routing protocols in mobile ad hoc networks and provided comparisons table among them. The protocols are divided into three main categories: (i) pro-active (table-driven), (ii) reactive (on-demand), (iii) hybrid protocols. For every these module, the representative we reviewed and compared some things about protocols. A relationship of three protocols, along with advantages and disadvantages has been presented in the form of table. There are different advantages and disadvantages in different routing protocols. In future work this can be helpful to get an overview of the existing protocols.

\section{ACKNOWLEDGMENTS}

Special thanks to Saheed Bhagat Singh College of Engg. and Tech, Punjab (India) for given that continuous Support during the work. I would like thanks to my supervisor, Mr. Vishal Arora, Assistant Professor, Department of Computer Science Engineering, SBS State Technical Campus, Ferozepur (Punjab), India.

\section{REFERENCES}

[1] Tseng, Yu-Chee, Sze-Yao Ni, Yuh-Shyan Chen, and JangPing Sheu. "The broadcast storm problem in a mobile ad hoc network." Wireless networks 8, no. 2-3 (2002): 153167.

[2] Sharma, Vishal, Harsukhpreet Singh, Mandip Kaur, and Vijay Banga. "Performance evaluation of reactive routing protocols in MANET networks using GSM based voice traffic applications." Optik-International Journal for Light and Electron Optics 124, no. 15 (2013).

[3] Singh, Jagtar, and Natasha Dhiman. "A Review Paper on Introduction to Mobile Ad Hoc Networks."

[4] Wang, Nen-Chung, Yung-Fa Huang, and Jhu-Chan Chen. "A stable weight-based on-demand routing protocol for mobile ad hoc networks." Information Sciences 177, no. 24 (2007): 5522-5537.

[5] Gorantala, Krishna. "Routing protocols in mobile ad-hoc networks." Master's Thesis in Computing Science, June 15 (2006).

[6] Zhang, Zhensheng. "Routing in intermittently connected mobile ad hoc networks and delay tolerant networks: overview and challenges." Communications Surveys \& Tutorials, IEEE 8, no. 1 (2006): 24-37.
[7] Kumar, Mukesh, Rahul Rishi, and D. K. Madan. "ISSUES AND CHALLENGES OF QUALITY OF SERVICE INMOBILE ADHOC NETWORK." Int $J$ of Computer Science \& Engineering Technology (IJCSET) (2010).

[8] Chitkara, Mahima, and Mohd Waseem Ahmad. "Review on MANET: Characteristics, Challenges, Imperatives and Routing Protocols." (2014).

[9] Haas, Zygmunt J., Jing Deng, Ben Liang, Panagiotis Papadimitratos, and Sajama Sajama. "Wireless ad hoc networks." Encyclopedia of Telecommunications (2002).

[10] Gomathi, S., R. Poonkuzhali, and K. Duraiswamy. "ROUTING PROTOCOLS FOR MOBILE AD-HOC NETWORKS PERFORMANCE ENHANCEMENT." Journal of Computer Applications 1, no. 4 (2008): 38

[11] Mohapatra, S., and P. Kanungo. "Performance analysis of AODV, DSR, OLSR and DSDV routing protocols using NS2 Simulator." Procedia Engineering 30 (2012): 69-76.

[12] Abolhasan, Mehran, Tadeusz Wysocki, and Eryk Dutkiewicz. "A review of routing protocols for mobile ad hoc networks." Ad hoc networks 2, no. 1 (2004): 1-22.

[13] Kumari, Suman, Sunil Maakar, Suresh Kumar, and R. K. Rathy. "Traffic pattern based performance comparison of AODV, DSDV \& OLSR MANET routing protocols using freeway mobility model." evaluation 8 (2011): 15.

[14] Tarique, Mohammed, Kemal E. Tepe, Sasan Adibi, and Shervin Erfani. "Survey of multipath routing protocols for mobile ad hoc networks." Journal of Network and Computer Applications 32, no. 6 (2009): 1125-1143.

[15] Mostafavi, Mohammad Ali, Ayyoub Akbari Moghanjoughi, and Hamid Mousavi. "A Review and Performance Analysis of Reactive and Proactive Routing Protocols on MANET." Network \& Communication Technologies 1, no. 2 (2012).

[16] Gupta, Anuj K., Harsh Sadawarti, and Anil K. Verma. "Review of various Routing Protocols for MANETs." International Journal of Information and Electronics Engineering 1, no. 3 (2011).

[17] Dai, Lillian Lei. "Proactive mobile wireless networks: an infrastructureless wireless network architecture for delaysensitive applications." $\mathrm{PhD}$ diss., Massachusetts Institute of Technology, 2008. 